\title{
Preconceito internalizado e comportamento sexual de risco em homossexuais masculinos
}

\author{
Internalized prejudice and sexual risk behavior among gay males
}

\begin{abstract}
Adriana Nunan
Psicóloga, Pós-Graduação em Comunicação Social, Mestre em Psicologia, e Doutora em Psicologia Clínica (PUC-Rio), Rio de Janeiro, RJ - Brasil, e-mail: adriananunan@adriananunan.com
\end{abstract}

\section{Resumo}

Apesar do surgimento, nas últimas décadas, de uma vasta gama de estudos relacionados à homossexualidade, pouco foi produzido sobre o tema do preconceito internalizado, definido aqui como a aceitação pelos indivíduos homossexuais das atitudes negativas veiculadas pela sociedade em relação a gays e lésbicas. Tendo como base conceitos oriundos da psicologia social, procede-se neste artigo, a partir da literatura existente, a uma investigação sobre o preconceito sexual internalizado e sua possível relação com comportamentos sexuais de risco entre determinados setores da população homossexual masculina. Investiga-se, particularmente, os fenômenos conhecidos como barebacking (prática de sexo anal sem uso de preservativo e com parceiros múltiplos e/ou desconhecidos) e bug chasing (tentativa de contrair, voluntariamente, o vírus do HIV por meio de relações sexuais desprotegidas com indivíduos soropositivos). Ao cabo do trabalho levantam-se algumas questões relacionadas à decisão consciente que algumas pessoas fazem por adotar práticas sexuais consideradas de alto risco.

Palavras-chave: Homossexualidade. Preconceito internalizado. Comportamento de risco. Sexo.

\begin{abstract}
Despite the emergence, in the last decades, of a vast range of studies related to homosexuality, little has been produced on the subject of internalized prejudice, defined here as the acceptance, by homosexuals, of society's negative attitudes towards gays and lesbians. Using social psychological concepts, this article proceeds to a theoretical investigation on internalized prejudice and its possible relation with high risk sexual behaviors among male homosexuals. It will investigate the behaviors known as barebacking (unprotected anal sex with multiple and/or unknown partners) and bug chasing (individuals who consciously try to acquire the HIV virus by having sex with HIV-positive people).
\end{abstract}


At the end of the article we discuss some issues regarding the conscious decision that some people make to engage in sexual behaviors that are considered to be of high risk.

Keywords: Homosexuality. Internalized prejudice. Risk behavior. Sex.

\section{Introduçáo}

\section{Preconceito sexual internalizado}

Indivíduos estigmatizados estão frequentemente expostos a ameaças diretas e indiretas à sua autoestima. Estereótipos de que os homossexuais são inferiores, que possuem defeitos de caráter moral, são mantidos tanto por instituições sociais (tais como família, escola, Igreja e Estado) como pelos meios de comunicação de massa em geral (Nunan, 2003). São imagens tão difundidas que se torna difícil deixar de internalizá-las em algum grau, sobretudo durante a infância (Pereira \& Leal, 2002). Gays que internalizam essas crenças podem se sentir inferiores aos heterossexuais e incapazes de alcançar objetivos que contradigam o preconceito.

Os eventos de vida negativos decorrentes do preconceito institucionalizado e da discriminação podem ser chamados de estressores externos, enquanto que os estressores internos seriam aqueles ligados ao preconceito internalizado. Em outras palavras, podese dizer que quando o estereótipo é muito forte ou pernicioso, membros do grupo alvo tendem a aceitálo e incorporá-lo à sua auto-imagem, fazendo com que sentimentos negativos com relação à própria orientação sexual sejam generalizados para o self como um todo.

O preconceito sexual internalizado pode ser definido sucintamente como a "aceitação pelos indivíduos homossexuais das atitudes negativas veiculadas pela sociedade em relação à homossexualidade" (Antunes \& Machado, 2005, p. 8). Esta aceitação resultaria em "sentimentos negativos sobre o self - principalmente culpa e vergonha de ser gay ou lésbica ou de experienciar desejo homossexual" (Downey \& Friedman, 1995, p. 435; tradução nossa). Em outras palavras, o sujeito passa a acreditar que o selfé inerentemente mau, sem valor ou repulsivo, e de que boa parte de seus problemas pessoais decorrem disto. De um modo geral, o preconceito internalizado se apresenta em um contínuo que vai desde questionamentos sobre seu próprio valor como indivíduo, até o ódio por si mesmo, estando correlacionado também com depressão, baixa autoestima, vergonha, culpa, medo, desconfiança, insegurança, ansiedade, queixas psicossomáticas, sentimentos de solidão, frustração, isolamento social, dificuldade de estabelecer e manter relacionamentos amorosos, violência doméstica, comportamento sexual de risco, abuso de álcool e drogas, transtornos alimentares e comportamento ou ideação suicida (Dew \& Chaney, 2005; Herek, Cogan, Gillis \& Glunt, 1997). Dificulta, igualmente, a adoção de uma identidade gay positiva e, no caso de sofrerem algum tipo de discriminação, esses indivíduos tendem a colocar a culpa em si mesmos (pois acreditam que mereceram o castigo), o que diminui ainda mais sua autoestima (Malyon, 1982; Sophie, 1987).

A correlação entre preconceito internalizado e alguns dos sintomas mencionados anteriormente já foi tratada extensamente em pesquisas anteriores (Nunan, 2004, 2007a, 2007b). O presente artigo se dedicará à análise da relação entre este tipo de preconceito e comportamentos sexuais de risco em homossexuais masculinos. Não obstante o fato de a literatura especializada ter encontrado correlações entre preconceito internalizado e determinados sintomas, isto não quer dizer que esta relação seja causal, direta ou que se estabeleça, invariavelmente, em todos os casos. O que postulamos é que, no caso de homossexuais que apresentam queixas clínicas tais como depressão, ansiedade, transtornos alimentares, dependência química ou violência doméstica, a influência do preconceito internalizado deve ser sempre avaliada como uma possibilidade (Nunan, 2007a).

\section{Utilizaçáo de preservativos e o medo da AIDS}

Determinadas práticas sexuais, sejam estas estimuladas pelo abuso de álcool e drogas (tal como veremos logo a seguir) ou por outros motivos (como é o caso do barebacking e do bug chasing, analisados mais adiante), têm provocado um aumento nos casos 
de transmissão do vírus HIV entre homossexuais nos Estados Unidos, Inglaterra e Austrália (Parker, 2003; Van de Ven, Prestage, Crawford, Grulich \& Kippax, 2000). No Brasil, dados do Ministério da Saúde revelam que a epidemia de AIDS está em um processo de redução persistente, embora pequena, com os casos de transmissão homossexual masculina mantendo-se em cerca de $20 \%{ }^{1}$ - número ainda elevado, considerando-se que apenas $8 \%$ da população adulta pode ser considerada homossexual (Nunan, 2007a).

Os dados sobre uso de preservativos entre homens que farem sexo com homens, ${ }^{2}$ no entanto, são mais preocupantes. De acordo com o levantamento do Monitoraids (2008), 59,8\% desses indivíduos usaram preservativo na última relação sexual; 80,7\% utilizaram na última relação sexual com um parceiro eventual; 44,4\% usaram preservativo regularmente com qualquer parceiro; $39,6 \%$ o fizeram com parceiro fixo; e $66,9 \%$ adotaram esse comportamento apenas com parceiros eventuais. Dados semelhantes foram encontrados por Carrara e Ramos (2005), que postulam que apenas $72,6 \%$ dos homossexuais, bissexuais e transgêneros entrevistados utilizavam preservativos em todas as relações sexuais, o que significa que quase $30 \%$ deste setor da população não usa preservativo ou não o faz de modo sistemático. Ainda de acordo com essa pesquisa, o uso de preservativo está hierarquizado segundo o caráter da relação sexual, isto é, na medida em que o relacionamento se torna mais estável ao longo do tempo, a utilização de preservativo cai significativamente. $\mathrm{Na}$ pesquisa de Antunes (2005), por exemplo, 52\% dos homossexuais pesquisados tiveram prática sexual de risco com parceiros fixos e $42 \%$ o fizeram com parceiros casuais. Informações colhidas pelo Censo GLS (2005) indicam, por sua vez, que apenas 50\% dos homossexuais utilizam preservativo em todas as relações, $29 \%$ na maioria das relações e $8 \%$ o faz esporadicamente. Por último, segundo dados de uma pesquisa realizada em São Paulo (Silva, Gonçalves, Pacca \& Hearst, 2004), 27,7\% dos homossexuais entrevistados disseram ter feito sexo anal desprotegido com um parceiro fixo, ao passo que 18,1\% dos sujeitos afirmaram ter tido comportamento semelhante com um parceiro ocasional. Em outras palavras, os dados acima nos levam a crer que um número elevado dos homossexuais masculinos não faz uso de preservativos em relações sexuais ou o faz apenas esporadicamente.

Não obstante os dados do Ministério da Saúde brasileiro apontarem para uma leve redução gradual da contaminação pelo HIV entre homossexuais masculinos, acreditamos, com outros autores (Buchalla, 2005; Martins, 2003), que este índice tenderá a aumentar no futuro, sobretudo pela utilização reduzida de preservativos em todas as relações sexuais, assim como um aumento no número de práticas sexuais de risco, tal como veremos a seguir. Além do HIV, ressaltamos que outras doenças sexualmente transmissíveis possuem elevada incidência entre homossexuais masculinos, incluindo hepatite (que pode evoluir para cirrose ou câncer), sífilis (que tem registrado um aumento de casos nos últimos anos), HPV (que também causa câncer anal) e LGV (doença causada por uma bactéria do grupo da clamídia que facilita a transmissão da hepatite C e do HIV). Lembramos que, de um modo geral, qualquer doença sexualmente transmissível aumenta o risco de infecção pelo vírus HIV.

Como nos apontam alguns estudos (Silva et al., 2004; Vanable, Ostrow, McKirnan, Taywaditep \& Hope, 2000), jovens que não experienciaram a devastação causada pelos primeiros anos da epidemia de AIDS (particularmente durante as décadas de 1980 e início de 1990), tendem a adotar comportamentos sexuais de risco, acreditando que mesmo que sejam infectados, o coquetel de remédios anti-HIV (utilizado desde 1996) prolongará indefinidamente suas vidas. Para esses indivíduos, o HIV passou a ser encarado como uma doença crônica, com a qual é possível conviver sem maiores transtornos. Esses dados são corroborados por Mansergh, Marks, Miller, Appleby e Murphy (2000), que sugerem que ter uma

1 Boletim Epidemiológico AIDS/DST, 2006.

2 O termo "homens que fazem sexo com homens" (HSH) é um conceito epidemiológico criado para referir-se a indivíduos que adotam práticas sexuais com pessoas do mesmo sexo biológico, mas que não se identificam como homossexuais. Apesar de acreditarmos que este conceito é útil para pesquisas em saúde pública, ele tem sido duramente criticado por setores do movimento homossexual que postulam que sua utilização reforça a invisibilidade dos gays. Mott (2003), por exemplo, sugere que ele seja substituído pela expressão “homens com práticas homossexuais”. Boletim Epidemiológico AIDS/DST, 2006. 
Nunan, A.

relação emocional próxima com uma pessoa HIVpositivo faz com que o indivíduo adote um número menor de comportamentos sexuais de risco, visto que esse passa a experienciar, mesmo que indiretamente, as consequências de ser portador do vírus da AIDS. De acordo com Kalichman, Nachimson, Cherry e Williams (1998), alguns indivíduos acreditam, equivocadamente, que homossexuais HIV-positivo que estão tomando o coquetel de remédios e possuem cargas virais muito baixas ou não detectáveis são menos propensos a transmitir o vírus e se tornam, portanto, mais seguros como parceiros sexuais. Da mesma forma, imagens cadavéricas de indivíduos morrendo de AIDS não são mais veiculadas, enquanto que os anúncios dos coquetéis de remédios apresentam fotografias de homens belos, atléticos e saudáveis inseridos em paisagens paradisíacas, ignorando os severos efeitos colaterais provocados por essas medicações.

Em outras palavras, pode-se dizer que na última década o medo provocado pela AIDS diminuiu consideravelmente, o que fez com que muitos indivíduos se preocupassem cada vez menos com a prevenção da doença. Scarce (1999) aponta ainda para outros motivos igualmente relevantes, tais como a falta de uma discussão verdadeiramente aberta sobre desejo, a dessensibilização provocada por décadas de campanhas em favor do uso de preservativos, e a resistência em adotar estratégias de redução de danos (nas quais as pessoas possam realizar escolhas informadas sobre o nível de risco ao qual querem se expor). Em suma, uma série de fatores distintos parecem ter contribuído para uma explosão de casos de HIV entre homossexuais masculinos jovens vivendo em grandes centros urbanos (Finnegan \& McNally, 2002).

\section{Abuso de álcool e drogas e o aumento de comportamentos sexuais de risco}

Outro fator apontado com frequência para explicar o aumento no número de homossexuais masculinos contaminados pelo HIV é o elevado índice de dependência química nesta população, tal como discutido em Nunan (2007a). De acordo com Bissell (1995), indivíduos sob o efeito de álcool ou drogas são incapazes de julgamentos racionais e de se preocupar com a utilização de seringas estéreis (no caso de drogas injetáveis) ou preservativos, caso mantenham relações sexuais. Esse fenômeno parece ocorrer mesmo entre pessoas que estão amplamente cientes dos riscos envolvidos nesses tipos de comportamento. Tal ideia é corroborada por diversos autores (Koblin, Chesney, Husnik \& Bozeman, 2003; Stall, Paul, Barrett, Crosby \& Bein, 1999), que apontam para o fato de que indivíduos que usam álcool ou drogas não praticam sexo seguro, a despeito de conhecimento prévio de técnicas de prevenção.

Álcool e drogas podem desinibir a atividade sexual (servindo como um "afrodisíaco", por exemplo), atuando em mecanismos do sistema nervoso central que aumentam a excitação (Crowe \& George, 1989), diminuindo a ansiedade (Levenson, Sher, Grossman, Newman \& Newlin, 1980), ou exacerbando a percepção de sensação imediata, ao mesmo tempo em que reduzem a habilidade de processar informação abstrata, incluindo normas de comportamento sexual seguro (Steele \& Josephs, 1990). Drogas tais como cocaína e crack também induziriam o sujeito a adotar comportamentos sexuais de risco por causa do aumento de libido e desinibição decorrentes da estimulação dopaminérgica (Chaisson et al., 1991). Vale mencionar aqui a teoria do modelo de interação biológica, que postula que durante o sexo anal determinadas drogas (particularmente cocaína, crack e maconha) relaxam o esfíncter anal, causando vasodilatação, irritação ou ressecamento de membranas mucosas, facilitando o trauma retal, o que por sua vez aumentaria o número de caminhos físicos para a infecção pelo vírus do HIV. Do mesmo modo, os efeitos imunossupressivos do álcool e de outras drogas podem tornar o organismo ainda mais suscetível à contaminação (Dean et al., 2000; Ostrow \& Shelby, 2000).

De acordo com McKirnan, Ostrow e Hope (1996), é possível, também, que um mecanismo de aprendizagem simples contribua para os efeitos de substâncias químicas nos comportamentos sexuais de risco. Tal como mencionado em Nunan (2003), bares e boates são importantes locais de socialização para muitos homossexuais, o que, ao longo do tempo, pode vir a criar uma forte associação positiva entre sexo e uso de substâncias (Crowe \& George, 1989). Por outro lado, alguns autores (Ostrow \& Shelby, 2000) têm postulado a ideia de que determinados indivíduos, querendo adotar comportamentos sexuais de risco, mas não tendo coragem suficiente para tomar esta decisão, usam drogas e álcool como uma "desculpa", uma estratégia cognitiva para escapar 
de suas inibições e medos. Independente da teoria explicativa adotada, pode-se dizer, com um razoável grau de certeza, que, sobretudo no caso da população homossexual masculina, drogas, álcool e HIV andam de mãos dadas (Hicks, 2000; Ostrow, 2000; Ross et al., 2001).

Ainda no que se refere à correlação entre dependência química e HIV, não podemos deixar de mencionar a explosão, nos últimos dez anos, do uso da droga metanfetamina (também conhecida como crystal) entre determinados subgrupos da comunidade homossexual masculina (Gorman, Morgan \& Lambert, 1995). Nos Estados Unidos a gravidade do problema fez com que cidades como Los Angeles, Nova York e São Francisco elaborassem campanhas de saúde pública voltadas exclusivamente para homossexuais que consomem metanfetamina. No Brasil, o ecstasy ainda parece ser a droga mais consumida pela população homossexual, mas, de acordo com algumas matérias jornalísticas (Buchalla, 2005), as anfetaminas vêm ganhando cada vez mais espaço.

A metanfetamina pode ser administrada de diversas formas, incluindo inalação oral (fumada), insuflação nasal (cheirada), absorção pela mucosa retal e de modo intravenoso (injetada), sendo este último método o mais utilizado por homossexuais (Sowder \& Beschner, 1993). Visto que os efeitos desta droga incluem desinibição e estimulação sexual, seu uso constante coloca os homossexuais em um risco elevadíssimo para infecção pelo HIV e por outras doenças sexualmente transmissíveis (Gorman et al., 1995). As anfetaminas, em geral, assim como a cocaína, tendem a ser consumidas por um pequeno subgrupo de indivíduos dentro da comunidade homossexual que praticam sexo anônimo ou com muitos parceiros. Isso se deve ao fato de que, tal como mencionado acima, essas drogas são grandes estimuladores da intensidade e atividade sexual, aumentando e prolongando a potência sexual.

Não obstante estas características, um dos efeitos colaterais das anfetaminas é uma impotência transitória, o que, por sua vez, faz com que o usuário combine o uso da droga com o de medicamentos tais como o Viagra $^{\circledR}$, gerando muitas vezes um coquetel potencialmente danoso de substâncias (Guss, 2000). Vale ressaltar que o Viagra ${ }^{\circledR}$ também pode ser misturado com ecstasy, caso no qual a substância (vendida pronta em formato de pílula) é chamada de "sextasy", podendo provocar, por exemplo, ataques cardíacos fulminantes ou danos permanentes ao pênis. Visto que, após o consumo destas substâncias, o desejo sexual é prolongado por até 14 horas, muitos desses indivíduos passam a fazer sexo anal receptivo, algumas vezes com muitos parceiros, o que aumenta significativamente o risco de infecção por HIV se medidas profiláticas não forem adotadas (Cabaj, 2000). O uso indevido do Viagra ${ }^{\circledR}$ também aumenta o risco de transmissão de doenças sexuais porque a medicação pode prolongar a intimidade e aumentar o tamanho de uma ereção, o que, por sua vez, potencializa a fricção e o risco de fissuras anais. Por último, mencionamos que a relação entre o uso de determinadas drogas e o vírus HIV também pode ser evidenciada pelo fato de que muitos indivíduos interrompem a medicação antiHIV no fim de semana (período durante o qual o ecstasy e as metanfetaminas são mais consumidos) com o intuito de evitar os efeitos da combinação dos remédios com as drogas, o que acaba causando resistência aos medicamentos, gerando tipos de vírus cada vez mais perigosos.

Além dos comportamentos de risco relacionados ao uso de substâncias químicas, determinadas práticas sexuais que ganharam adeptos nos últimos dez anos, sobretudo por meio da internet, têm tido um impacto significativo na transmissão do vírus HIV entre homossexuais masculinos. Dentre essas práticas cita-se, por sua relevância, o barebacking e o bug chasing.

\section{Barebacking}

O barebacking (também chamado de "sexo cru" ou "pele-com-pele") é uma prática sexual na qual o indivíduo se expõe premeditada e voluntariamente a relacionamentos sexuais de alto risco (isto é, pratica sexo anal sem uso de preservativo e com parceiros múltiplos e/ou desconhecidos), unindo prazer sexual a uma sensação de "liberdade", que pode ou não incluir a contaminação pelo vírus HIV. A palavra bareback pode ser traduzida por "traseiro careca" ou "cavalgada sem sela" - este último termo parece ter sido tomado emprestado do hipismo, no qual ele é aplicado a cavalos. Não obstante o sexo anal sem proteção ter sido uma prática sexual relativamente comum na comunidade gay até a década de 80, o surgimento da AIDS fez com que esse tipo de comportamento tivesse que ser rapidamente modificado com o intuito de evitar que a 
Nunan, A.

epidemia se alastrasse ainda mais. $\mathrm{O}$ barebacking, no entanto, foi resgatado a partir dos anos 90 por um subgrupo da comunidade homossexual que alega que a prática de sexo sem proteção é um direito de escolha na busca por prazer e intimidade e uma volta à liberdade sexual característica da década de 70. De acordo com Martins (2003), um dos aspectos centrais da definição do barebacking é a intencionalidade: o indivíduo consciente e racionalmente procura sexo anal sem proteção, o que distingue este comportamento de descuido, falta de planejamento ou decisões espontâneas no que se refere ao uso de preservativos. Outro aspecto crucial para a definição é que o parceiro sexual é frequentemente "avulso", ou seja, o comportamento não se insere em um contexto de sexo seguro negociado entre o indivíduo e seu companheiro estável. Vale ressaltar que esse subgrupo da comunidade homossexual se encontra amplamente ciente das formas de contágio e prevenção do HIV, o que torna o barebacking uma escolha consciente (Santos, 2004).

Tal como mencionado anteriormente, essa prática parece ter se disseminado a partir da internet, onde atualmente existem diversos sites e grupos dedicados ao barebacking, cujo número vem crescendo rapidamente a cada ano (Halkitis, Parsons \& Wilton, 2003). Para esses indivíduos, a internet (uma maneira rápida, fácil e anônima de encontrar novos parceiros) desempenha o papel das saunas gays e quartos escuros ${ }^{3}$ do início da década de 80 , quando a AIDS começou a se disseminar entre os homossexuais masculinos. Vale frisar, no entanto, que apesar da internet facilitar esses tipos de encontros, ela, em si mesma, não os estimula, o que fica evidenciado pelo fato de que bares, boates e saunas ainda são considerados locais importantes para encontrar eventuais parceiros sexuais. De acordo com Suarez e Miller (2001), também não se sabe ao certo se indivíduos que se identificam como barebackers não adotam práticas de sexo seguro de um modo geral ou se aderiram ao barebacking recentemente. Identificar o motivo desse comportamento parece crucial para elaborar estratégias de prevenção de HIV mais eficazes.
O barebacking é mais frequentemente praticado em festas fechadas (geralmente na residência de um dos participantes), durante fins de semana (pois os eventos podem durar de algumas horas a até dois dias), e com o número de participantes (em torno de dez pessoas) variando de acordo com o tamanho do local. Diversas preferências sexuais podem fazer parte do encontro, incluindo sexo oral com ingestão de sêmen, sadomasoquismo, dupla penetração, fist fucking (penetração anal pelo punho do parceiro) e coprofilia, por exemplo. Em muitas dessas festas, álcool e drogas são amplamente consumidos, assim como medicações tais como o Viagra ${ }^{\circledR}$, com o objetivo de prolongar as ereções. Mencionamos que, apesar do barebacking ser geralmente praticado em festas, isto não quer dizer que ele não faça parte do comportamento sexual diário de muitos indivíduos.

De acordo com uma pesquisa realizada por Mansergh et al. (2002), 14\% dos homossexuais entrevistados haviam praticado barebacking nos últimos dois anos, sendo que a maioria destes indivíduos era HIV-positivo. Vale ressaltar que apesar da maior parte dos indivíduos optar por fazer sexo com pessoas de status sorológico idêntico (isto é, sujeitos HIV-positivos só se relacionavam com outros HIVpositivos, e HIV-negativos só faziam sexo com outros HIV-negativos), ${ }^{4}$ muitos mantinham relações sexuais com indivíduos de status sorológico discordante ou sobre os quais não tinham informação. Esses dados são similares aos encontrados por outros autores (Ekstrand, Stall, Paul, Osmond \& Coates, 1999; Halkitis \& Parsons, 2003), que indicam que aproximadamente metade dos indivíduos que praticam sexo de risco o fazem com parceiros de status sorológico distinto ou desconhecido.

Escolher parceiros sexuais com base em informações sobre seu status sorológico é arriscado, no sentido de que o indivíduo pode mentir ou simplesmente não saber que está contaminado (Hays et al., 1997; Rowatt, Cunningham \& Druen, 1999). Outros sujeitos fundamentam suas decisões sobre o status sorológico do parceiro com base em dados "intuitivos", tais como aparência, idade, personalidade, comportamento, setting e discussão ou não

\footnotetext{
3 Quartos escuros (chamados em inglês de darkrooms) são salas com pouca ou nenhuma iluminação, frequentemente localizadas em boates, que se destinam única e exclusivamente à prática de sexo casual e anônimo.

4 Esta prática é chamada de soro-seleção, e envolve homens que escolhem parceiros sexuais baseados no status sorológico comum deles, isto é, na presença ou ausência de anticorpos no sangue a um agente infeccioso particular (no caso, o vírus do HIV).
} 
sobre o uso de preservativo (Santos, 2004; Suarez \& Miller, 2001), informações estas claramenteincapazes de predizer se um indivíduo é ou não HIV-positivo. Aponta-se aqui também para o fato de que, de acordo com a pesquisa de Mansergh et al. (2002), citada anteriormente, mais da metade dos sujeitos que haviam praticado barebacking estavam sob o efeito de álcool ou drogas (particularmente metanfetamina) na ocasião. O estudo de Halkitis, Parsons e Wilton (2003) encontrou dados semelhantes, isto é, os indivíduos se relacionavam com sujeitos com o mesmo status sorológico que eles, mas homossexuais HIV-positivo relataram uma porcentagem maior de episódios de barebacking, assim como um número mais elevado de parceiros sexuais. De acordo com nossa análise, esses dados podem ser explicados de diversas formas: pode ser que o indivíduo tenha contraído HIV pro conta de um número maior de contatos sexuais de risco; aqueles que já são HIV-positivo podem achar que não têm nada a perder praticando barebacking; ou é possível que homens HIV-negativo e positivo tenham índices idênticos de barebacking, mas aqueles que são HIV-negativo têm vergonha de admitir que adotam este comportamento sexual.

Praticantes do barebacking justificam esse comportamento alegando que preservativos devem ser uma escolha e, consequentemente, uma responsabilidade, mas nunca uma imposição social. Para esses indivíduos, o sexo sem restrições é excitante, permitindo que o sujeito alcance uma grande "estimulação" ou "satisfação" física, assim como uma maior "conexão espiritual" com o parceiro (Jesus, 2002; Mansergh et al., 2002). Neste sentido, podese pensar que o preservativo (uma barreira física) representa uma barreira emocional para muitos indivíduos. Gus (2000) sugere, igualmente, que a qualidade "pervertida" desse tipo de comportamento possa contribuir para a excitação, na medida em que a procura por um "sexo puro" oferece uma emoção transgressora, isto é, a ideia de que "é divertido ser mau”. Desse modo, podemos compreender esse sistema de valores quase como uma ideologia, uma rebelião contra a "ditadura" do sexo seguro, contra a "tirania das camisinhas" e em favor da "liberdade do desejo" (Ostrow \& Shelby, 2000). Vale ressaltar que muitos dos indivíduos que adotam essa prática se intitulam barebackers, isto é, adotam uma identidade específica, lutando, igualmente, pelo direito de terem relações sexuais da forma que quiserem. Lembramos, também, que a grande maioria dos barebackers possui preconceito contra homossexuais efeminados, adotando o raciocínio de que "sexo sem camisinha é coisa de macho, porque requer coragem". Este pensamento foi corroborado pelos achados de Halkitis e Parsons (2003), que observaram uma correlação entre barebacking e a ideia de sexo como uma definição de masculinidade.

Nos Estados Unidos e na Europa, o fenômeno do barebacking tem atraído a atenção da mídia e de pesquisadores, gerando, simultaneamente, uma enorme controvérsia dentro da comunidade homossexual, que, se por um lado critica este comportamento, também o glamouriza em capas de revistas (Gendin, 1999). No Brasil, onde o barebacking começou a se propagar a partir de 2002, apenas Martins (2003) e Santos (2004) têm pesquisado o assunto. Dentro da comunidade homossexual brasileira, essa prática, considerada tabu, tem sido duramente criticada por alguns líderes do movimento gay, tais como Beto de Jesus (2002) e Luiz Mott (2005), mas sua gravidade permanece largamente subestimada pela maioria da população. De acordo com Jesus (2002), por exemplo, muitos especialistas na área de saúde acreditam que alertar a população sobre o barebacking ajudaria a divulgar este tipo de prática, ao passo que grupos religiosos conservadores a utilizam como um argumento em favor da ideia de que os homossexuais continuam sendo um grupo de risco. Apesar das pesquisas com relação a esse tema ainda serem relativamente escassas, os autores que se dedicam ao assunto apontam motivações psicossociais semelhantes para explicar porque determinados indivíduos se expõem, voluntariamente, a relações sexuais de alto risco.

Em primeiro lugar, autores como Friedman e Downey (1994) postulam que o preconceito internalizado possui influência crucial no que se refere à prática do barebacking, seja porque o indivíduo está deprimido ou tem baixa autoestima (isto é, não acredita que sua saúde seja merecedora de cuidados), seja como um comportamento suicida ou de autopunição (visto que o indivíduo se considera uma pessoa "doente", "ruim" ou "defeituosa", cuja única saída é contaminar-se com HIV e morrer). Esses dados são corroborados por Adam, Sears e Schellenberg (2000), que postulam que estados de humor e autoimagens negativas estão associadas com comportamentos sexuais de risco. Outros autores (Hospers, Molenaar \&Kok, 1994), encontraram, igualmente, associações entre depressão e comportamentos sexuais de risco. 
Odets (1995), por sua vez, relata uma correlação entre práticas sexuais de risco e um desejo consciente ou inconsciente de autodestruição. Crises ligadas à assunção da homossexualidade, particularmente entre indivíduos previamente casados com mulheres ou sujeitos profundamente religiosos, também tendem a se correlacionar com práticas sexuais de risco. A pesquisa de Adam et al. (2000) encontrou um dado semelhante: homossexuais que foram criados com valores religiosos conservadores eram os que mais relatavam práticas sexuais de risco e ideias autodestrutivas.

Tendo "caído em tentação" por meio da expressão do seu desejo homossexual, eles se encontravam presos no discurso da "AIDS como um castigo" propagado pelas Igrejas conservadoras, o que, ironicamente, pode acabar se transformando em uma profecia auto-realizadora, no sentido de aumentar o risco de exposição ao HIV através do sexo pouco seguro (Adam et al., 2000, p. 30, tradução nossa).

Nesse sentido, podemos dizer que sexo seguro torna-se irrelevante quando existe perspectiva de retribuição divina. De acordo com Adam e Sears (1996), em alguns casos, indivíduos HIV-positivo imersos em tradições religiosas conservadoras continuariam lutando contra essa lógica da punição anos após o diagnóstico. O estudo de Nicholson e Long (1990), por sua vez, postula que homossexuais HIV-positivo que sofrem de preconceito internalizado tendem a se culpar pela doença. Dupras (1994) menciona, ainda, que estes indivíduos apresentam uma série de dificuldades de ajustamento sexual, no sentido de que o sexo representaria duas transgressões simultâneas: a homossexualidade e o vírus HIV.

Jovens homossexuais com preconceito internalizado também podem se sentir pessimistas com relação à ideia de envelhecer como um homem gay, e acabar achando que contrair HIV é uma forma aceitável de escapar de um futuro encarado por eles como sombrio (Suarez \& Miller, 2001). Sujeitos que acabaram de receber o diagnóstico de HIV-positivo também podem achar que não têm nada a perder, raciocínio semelhante ao adotado por indivíduos que acreditavam que iam morrer mas que se mantiveram vivos graças aos coquetéis de remédios. Um dos entrevistados de Martins (2003) também sugere uma explicação bastante interessante para esse fenômeno: visto que os homossexuais ainda são encarados com um grupo de risco pela sociedade mais ampla, o comportamento sexual sem repressões (isto é, sem preservativos) dos barebackers seria uma tentativa de assemelhar-se aos heterossexuais, que, de acordo com esse raciocínio, são capazes de vivenciar uma sexualidade livre do fantasma da AIDS. O que esses sujeitos esquecem, no entanto, é que não existem mais "grupos de risco", e sim "comportamentos de risco".

\section{Bug chasing}

Não obstante alguns barebackers compartilharem a valorização do HIV como algo que lhes confere erotismo e um status social mais elevado dentro da comunidade gay, essa prática sexual deve ser diferenciada do bug chasing, na qual o indivíduo tenta, voluntariamente, contrair o vírus do HIV por meio de relações sexuais desprotegidas com sujeitos HIV-positivo. Aparentemente, não há muita divergência quanto ao fato do barebacking ser imprudente, mas isto não quer dizer, necessariamente, que seus praticantes busquem uma doença sexualmente transmissível mais do que qualquer heterossexual que pratique sexo sem preservativo. $\mathrm{Na}$ maioria das vezes, no entanto, barebacking e bug chasing são comportamentos intimamente ligados entre si, posto que praticar sexo anal conscientemente sem o uso de preservativos coloca o sujeito em grande risco de contrair o vírus do HIV.

O bug chasing, expressão que pode ser traduzida como "caçando o vírus", é uma prática que ganhou força no início da década de 90, aproximadamente na mesma época que o barebacking, sendo também divulgada primariamente na internet. De acordo com Gauthier e Forsyth (1999), o bug chasing provavelmente existe desde o começo da epidemia de AIDS, mas se tornou mais frequente com o advento da internet, que facilitou o encontro de parceiros sexuais. Inicialmente considerado uma "lenda urbana", o bug chasing ganhou notoriedade internacional com um documentário de 2002 intitulado The Gift, da diretora norte-americana Louise Hogarth. Apesar desse comportamento ser considerado chocante tanto pela comunidade homossexual como pela sociedade mais ampla, pesquisas científicas sobre o assunto são praticamente inexistentes, sobretudo pela dificuldade de encontrar indivíduos 
que admitam abertamente que estão tentando se contaminar com HIV (Barker, 2002).

Para compreendermos o bug chasing devemos, em primeiro lugar, estar familiarizados com a linguagem própria utilizada por esses indivíduos. Assim, dentre os termos mais comuns citamos: bug chaser (ou "caçador de vírus", sujeito HIV-negativo que quer se tornar HIV-positivo); the gift ("o presente", isto é, o vírus HIV); gift giver ("doador do presente", ou seja, indivíduos HIV-positivo que buscam contaminar outras pessoas); russian roulette parties ("festas de roleta russa", onde existem pessoas HIV-positivo e HIV-negativo); bug brother (que pode ser traduzido como "irmão de vírus", isto é, grupo de pessoas HIV-positivo); charged cum ou poz. cum ("ejaculação carregada" ou "positiva"; em outras palavras, o sêmen com HIV); e conversion parties (ou "festas de conversão", onde o indivíduo HIV-negativo se torna HIV-positivo). Acrescentamos que nessas festas os bug chasers são convertidos em gift givers, situação que lhes confere um status maior no grupo e que, portanto, é celebrada por amigos frequentemente convidados a participarem do acontecimento. Para todas essas pessoas, o sêmen contaminado com o vírus do HIV possui um forte apelo erótico (Scarce, 1999). Vale lembrar que, assim como acontece com o barebacking, a prática do bug chasing não se limita a festas esporádicas, podendo ocorrer, por exemplo, entre apenas dois indivíduos.

No começo dos anos 80 , na comunidade gay, circulou brevemente a proposta de tatuar os soropositivos, de forma que seus parceiros fossem imediatamente informados e tomassem as precauções necessárias. A idéia foi recusada como forma abjeta de discriminação. A ironia é que, hoje, a tatuagem volta, mas não como marca de exclusão. Ao contrário, o símbolo convencional que designa o perigo biológico de contaminação é tatuado por sujeitos soropositivos perto do púbis como um incentivo sexual. Pela mesma razão, alguns escrevem no bíceps "HIV-poz". Outros escrevem "HIVneg" e saem à caça do vírus para poder, enfim, barrar o "neg" (Calligaris, 2003).

Diversos fatores têm sido citados como explicações para o comportamento do bug chasing, dentre os quais destacamos o preconceito, tanto internalizado quanto institucionalizado, ideia com a qual a maioria dos autores parece concordar (Barker, 2002). Parker (2003), por exemplo, sugere que alguns homossexuais jovens tentariam contrair o HIV como uma forma de expressão deidentidade, isto é, receber um diagnóstico de soropositividade seria um sinal de reconhecimento de que se é verdadeiramente gay. Neste sentido, o HIV é visto como um prêmio que permite ao indivíduo pertencer tanto à comunidade gay mais ampla quanto àquela formada pelos soropositivos, que passaram a ser reverenciados pela subcultura homossexual como "soldados em uma guerra santa". Em outras palavras, a identidade do indivíduo HIV-positivo teria sido desestigmatizada, passando de desviante para carismática (Gauthier \& Forsyth, 1999). Para indivíduos que se sentem extremamente solitários (pela morte de companheiros e amigos) e marginalizados (pelas rígidas normas estéticas prevalentes na subcultura homossexual), essa nova identidade "positiva" (em ambos sentidos) pode se tornar extremamente sedutora. Para alguns sujeitos, por exemplo, a AIDS, assim como outras doenças mortais, pode trazer significado para a vida, transformação esta que, provavelmente, não seria possível em outras situações.

Outra explicação apontada por Gauthier e Forsyth (1999) é a ideia de que indivíduos que sobreviveram aos primeiros anos da epidemia se sentem culpados de continuarem vivos enquanto muitos de seus companheiros e amigos morreram. É possível que os bug chasers estejam mais dispostos do que outros sujeitos a expiar esta culpa de terem sobrevivido por tantos anos ativamente "caçando o vírus". Em um sentido semelhante, encontramos homossexuais que acreditam que estão fadados a desenvolver AIDS (Finnegan \& McNally, 2002), o que os leva a tomar o controle da situação adotando o seguinte raciocínio: "vou pegar de uma vez e acabar com essa ansiedade". Nestes casos, o resultado de HIV-positivo é encarado pelo indivíduo como um alívio (Gendin, 1999):

Muitos homens gays têm visto amigos e companheiros morrer e podem sentir que o HIV é uma inevitabilidade que eles estão cansados de esperar. Para homens HIV-negativo que estão vivendo em uma comunidade de homens HIVpositivo, ou para aqueles em relacionamentos sorodiscordantes (um parceiro é positivo, o outro negativo), o HIV pode ser um equalizador. Ele pode ser um meio de aceitação e status, 
uma forma de compreender profundamente as experiências de tantos outros homens gays e uma entrada em grupos de apoio mútuo, retiros e diversos serviços de saúde alternativos. Muitos de nós sabemos o que significa sentir-se socialmente isolado e rejeitado (Barker, 2002, p. 7 , tradução nossa).

No caso de casais sorodiscordantes, por exemplo, o parceiro que é HIV-negativo busca contrair voluntariamente o vírus do HIV com o objetivo de eliminar o uso de preservativos da relação sexual (o que, como vimos acima, proporcionaria maior "intimidade"), assim como de experienciar, com seu parceiro, problemas decorrentes da soropositividade, da AIDS e da proximidade da morte, igualando o status de ambos no relacionamento. De acordo com Scarce (1999), muitos praticantes de bug chasing acreditam que, quando são contaminados pelo parceiro, uma ligação espiritual eterna é estabelecida entre eles, conexão esta que dura a vida toda. Com frequência esses indivíduos utilizam o conhecimento científico de como o vírus HIV se propaga no organismo humano para romancear o processo de contaminação. Visto que o vírus invade a célula hospedeira, incorporando-se a ela, tecnicamente poderia-se dizer que o DNA de um organismo é combinado com o de outro para criar uma forma nova de vida. Assim, essas pessoas equiparam o bug chasing com "reprodução" e a infecção como "fertilização". Alguns homossexuais HIV-negativo tentam conscientemente escolher o indivíduo que irá ser o "pai" de sua infecção. Interessante ressaltar que, segundo Koblin et al. (2003), aproximadamente $37 \%$ dos homossexuais cujos parceiros são HIV-positivo praticam sexo sem proteção. Estes dados não indicam, necessariamente, que esses sujeitos sejam bug chasers, mas ressaltam a elevada incidência de relações sexuais desprotegidas entre casais sorodiscordantes.

\section{Consideraçóes finais}

À guisa de conclusão, gostaríamos de mencionar que outros fatores parecem influenciar na decisão consciente que muitos homossexuais fazem por adotar práticas sexuais de risco. Cabaj (2000), por exemplo, que entrevistou homossexuais moradores de rua, concorda com Barker (2002) no sentido de que muitos indivíduos (particularmente os adolescentes), tentariam se contaminar voluntariamente com o vírus do HIV para poderem obter determinados benefícios médicos e sociais. Jesus (2002), por sua vez, sugere que a soropositividade é entendida como uma liberação do sexo seguro, que possibilitaria um retorno à sexualidade sem limites experienciada na década de 70 .

Percebe-se que aqui não existem informações sobre aderência ao tratamento e aos efeitos colaterais provenientes do mesmo. [...] Ou mesmo, não se fala em re-infecção, em aumento de carga viral, no desencadeamento da queda de imunidade e novos sintomas, além da possibilidade de um tipo diferente de vírus que não responde à terapia anti-retroviral em uso, além de todas as outras DSTs nem sempre isentas de riscos graves para seus portadores (Jesus, 2002, p. 3).

Não podemos esquecer ainda de mencionar aqueles indivíduos que praticam o barebacking e o bug chasing por mera diversão, isto é, como comportamentos sexuais "radicais" que proporcionam uma alta dose de adrenalina, tal como acontece quando se brinca de roleta russa, por exemplo. De acordo com Gauthier e Forsyth (1999), eles acreditam que a satisfação sexual é aumentada em comportamentos sexuais de altíssimo risco, nas quais "flertariam com a morte". E, tal como acontece com os barebackers, muitos bug chasers adotam uma identidade específica.

Ironicamente, essas práticas podem ser compreendidas como uma internalização do estereótipo de que os homossexuais são disseminadores da AIDS, uma espécie de profecia autorrealizadora que reforça tanto o preconceito institucionalizado quanto o internalizado. Também não se pode descartar a hipótese de que transtornos de personalidade específicos estejam correlacionados com o comportamento do bug chasing, tema este que precisa ser melhor investigado. Seja qual for o motivo que leva um indivíduo a ser barebacker ou bug chaser (preconceito internalizado, autodestruição, transtorno psíquico, extrema pobreza ou simples entretenimento), um número maior de pesquisas sobre esses fenômenos precisa ser realizada, sobretudo pelo elevado custo social, médico e legal que comportamentos sexuais dessa natureza geram para a sociedade mais ampla. 


\section{Referências}

Adam, B. D., \& Sears, A. (1996). Experiencing HIV: Personal, family, and work relationships. New York: Columbia University Press.

Adam, B. D., Sears, A., \& Schellenberg, E. G. (2000). Accounting for unsafe sex: Interviews with men who have sex with men. The Journal of Sex Research, 37(1), 24-36.

Antunes, M. C. (2005). Territórios de vulnerabilidade ao HIV: Homossexualidades masculinas em São Paulo. Tese de Doutorado, Instituto de Psicologia, Universidade de São Paulo, São Paulo.

Antunes, R., \& Machado, C. (2005). Dupla invisibilidade: A violência nas relações homossexuais. Psychologica, 39, 167-187.

Barker, A. (2002). Bug chasing: Why do people deliberately seek to get infected? Living +, Nov./Dec., 6-7.

Bissell,L. (1995). Foreword. In R. J. Kus (1995). Addiction and recovery in gay and lesbian persons (pp. 19-23). New York: Harrington Park Press.

Boletim Epidemiológico AIDS/DST 2006. Site do Programa Nacional de DST e AIDS do Ministério da Saúde. Recuperado em 30 out. 2008, em http:/ / www.aids.gov.br

Buchalla, A. P. (2005). Liberou geral para a AIDS. Revista Veja, 38(8), 74-75.

Cabaj, R. P. (2000). Substance abuse, internalized homophobia, and gay men and lesbians: Psychodynamic issues and clinical implications. In J. R. Guss, \& J. Drescher (Ed.). Addictions in the gay and lesbian community. (pp. 5-24). New York: Haworth Medical Press.

Calligaris, C. (2003). "O Presente" do mix Brasil: O sexo na cidade, Folha de São Paulo, 10 ago, Caderno Mais.

Carrara, S., \& Ramos, S. (2005). Política, direitos, violência e homossexualidade - pesquisa $9^{a}$ parada do orgulho GLBT - Rio 2004. Rio de Janeiro: Centro Latino-Americano em Sexualidade e Direitos Humanos - IMS/UERJ.

Censo GLS. (2005). Instituto de pesquisa e cultura GLS: Uma joint-venture entre as empresas GLS Planet e JUMP Pesquisas. Recuperado em: 5 ago. 2006, em www.censogls.com.br
Chaisson, M. A., Stoneburner, R. L., Hildebrandt, D. S., Ewing, W. E., Telzak, E. E., \& Jaffe, H. W. (1991). Heterosexual transmission of HIV-1 associated with the use of smokable freebase cocaine (crack). AIDS, 5, 1121-1126.

Crowe, L. C., \& George, W. H. (1989). Alcohol and human sexuality: Review and integration. Psychological Bulletin, 105, 374-386.

Dean, L., Meyer, H. H., Robinson, K., Sell, R. L., Sember, R., Silenzio, V. M. B., et al. (2000). Lesbian, gay, bisexual, and transgender health: Findings and concerns. Journal of the Gay and Lesbian Medical Association, 4(3), 101-151.

Dew, B. J., \& Chaney, M. P. (2005). The relationship among sexual compulsivity, internalized homophobia, and HIV at-risk sexual behavior in gay and bisexual male users of internet chat rooms. Sexual Addiction \& Compulsivity, 12(4), 259-273.

Downey,J. I., \& Friedman, R. C. (1995). Internalized homophobia in lesbian relationships. Journal of the American Academy of Psychoanalysis, 23(3), 435-447.

Dupras, A. (1994). Internalized homophobia and psychosexual adjustment among gay men. Psychological Reports, 75(1), 23-28.

Ekstrand, M. L., Stall, R. D., Paul, J. P., Osmond, D. H., \& Coates, T. J. (1999). Gay men report high rates of unprotected anal sex with partners of unknown or discordant HIV status. AIDS, 13(12), 1525-1533.

Finnegan, D. G., \& McNally, E. B. (2002). Counseling lesbian, gay, bisexual, and transgender substance abusers: Dual identities. New York: The Haworth Press.

Friedman, R. C., \& Downey, J. I. (1994). Homosexuality. The New England Journal of Medicine, 331(14), 923-930.

Gauthier, D. K., \& Forsyth, C.J. (1999). Bareback sex, bug chasers, and the gift of death. Deviant Behavior, 20(1), 85-100.

Gendin, S. (1999). They shoot barebackers, don't they? POZ Magazine, 48-69.

Gorman, E. M., Morgan, P., \& Lambert, E. Y. (1995). Qualitative research considerations and other issues in the study of methamphetamine use among men who have sex with other men. In E. Y. Lambert, R. S. Ashery, \& R. H. Needle (Ed.). Qualitative methods in drug abuse and HIV research. (pp. 156-181). Washington, DC: NIDA Research Monograph Series. 
Guss, J. R. (2000). Sex like you can't even imagine: "Crystal", crack and gay men. In J. R. Guss, \& J. Drescher (Ed.). Addictions in the gay and lesbian community. (pp. 105-122). New York: Haworth Medical Press.

Halkitis, P. N., \& Parsons, J. T. (2003). Intentional unsafe sex (barebacking) among HIV-positive gay men who seek sexual partners on the internet. AIDS, 15(3), 367-378.

Halkitis, P. N., Parsons, J. T., \& Wilton, L. (2003). Barebacking among gay and bisexual men in New York City: Explanations for the emergence of intentional unsafe behavior. Archives of Sexual Behavior, 32(4), 351-357.

Hays, R. B., Paul, J., Ekstrand, M. L., Kegeles, S. M., Stall, R., \& Coates, T.J. (1997). Actual versus perceived HIV status, sexual behaviors and predictors of unprotected sex among young gay and bisexual men who identify as HIV-negative, HIV-positive and Untested. AIDS, 11(12), 1495-1502.

Herek, G. M., Cogan, J. C., Gillis, J. R., \& Glunt, E. K. (1997). Correlates of internalized homophobia in a community sample of lesbians and gay men. Journal of the Gay and Lesbian Medical Association, 2(1), 17-25.

Hicks, D. (2000). The importance of specialized treatment programs for lesbian and gay patients. In J. R. Guss, \& J. Drescher (Ed.). Addictions in the Gay and Lesbian Community. (pp. 81-94). New York: Haworth Medical Press.

Hospers, H., Molenaar, S., \& Kok, G. (1994). Focus group interviews with risk-taking gay men. Patient Education and Counseling, 24(3), 299-306.

Jesus, B. de. (2002). Barebacking. Brasília: Programa Nacional de DST/AIDS, Ministério da Saúde.

Kalichman, S. C., Nachimson, D., Cherry, C., \& Williams, E. (1998). AIDS treatment advances and behavioral prevention set-backs: Implications of reduced threat perceptions. Health Psychology, 17, 546-550.

Koblin, B. A., Chesney, M. A., Husnik, M. J., \& Bozeman, S. (2003). High-Risk behaviors among men who have sex with men in 6 US cities: Baseline data from the EXPLORE study. American Journal of Public Health, 93(6), 926-932.
Levenson, R. W., Sher, K. J., Grossman, L. M., Newman, J., \& Newlin, D. B. (1980). Alcohol and stress response dampening: Pharmacological effects, expectancy, and tension reduction. Journal of Abnormal Psychology, 89, 528-538.

Malyon, A. K. (1982). Psychotherapeutic implications of internalized homophobia in gay men. Journal of Homosexuality, 7(2-3), 59-69.

Mansergh, G., Marks, G., Colfax, G. N. B., Guzman, R. B., Rader, M. A., \& Buchbinder, S. B. (2002). "Barebacking" in a diverse sample of men who have sex with men. AIDS, 16(4), 653-659.

Mansergh, G., Marks, G., Miller, L. A., Appleby, P. R. A., \& Murphy, S. A. (2000). Is "knowing people with HIV/AIDS" associated with safer sex in men who have sex with men? AIDS, 14(12), 1845-1851.

Martins, M. C. (2003). High-risk sexual behavior: The rising of the "bareback" subculture in Brazil. [Paper] In 8th World STI/AIDS Congress. Punta del Este, Uruguay.

McKirnan, D. J., Ostrow, D. G., \& Hope, B. (1996). Sex, drugs, and escape: A psychological model of HIVrisky sexual behaviors. AIDS Care, 8(6), 655-669.

Mott, L. (2003). Homossexualidade: Mitos e verdades. Salvador: Grupo Gay da Bahia.

Nicholson, W. D., \& Long, B. C. (1990). Self-esteem, social support, internalized homophobia, and coping strategies of HIV+ gay men. Journal of Consulting and Clinical Psychology, 58(6), 873-876.

Nunan, A. (2003). Homossexualidade: Do preconceito aos padrões de consumo. Rio de Janeiro: Caravansarai.

Nunan, A. (2004). Violência doméstica entre casais homossexuais: O segundo armário? PSICO, 35(1), 69-78.

Nunan, A. (2007a). Homossexualidade e discriminação: $\mathbf{O}$ preconceito sexual internalizado. Tese de Doutorado, Departamento de Psicologia, Pontifícia Universidade Católica do Rio de Janeiro.

Nunan, A. (2007b). Influência do preconceito internalizado na conjugalidade homossexual masculina. In M. Grossi, A. P. Uziel, \& L. Mello (Org.). Conjugalidades, parentalidades e identidades lésbicas, gays e travestis. (pp. 47-67). Rio de Janeiro: Garamond. 
Odets, W. (1995). In the shadow of the epidemic: Being HIV-negative in the age of AIDS. North Carolina: Duke University Press.

Ostrow, D. G. (2000). The role of drugs in the sexual lives of MSM: Continuing barriers to researching this question. AIDS and Behavior, 4(2), 205-219.

Ostrow, D. G., \& Shelby, R. D. (2000). Psychoanalytic and behavioral approaches to drug-related sexual risk taking: a preliminary conceptual and clinical integration. In Guss, J. R., \& Drescher, J. (Ed.). Addictions in the gay and lesbian community. (pp. 123-139). New York: Haworth Medical Press.

Parker, M. (2003). Unsafe sex in london's backrooms. [Paper] In BA Festival of Science Challenging Medical Wisdom: Anthropology and health care in the 21st century. Wisdom: Autor.

Pereira, H., \& Leal, I. (2002). A homofobia internalizada e os comportamentos para a saúde numa amostra de homens homossexuais. Análise Psicológica, 1(20), 107-113.

Ross, M. W., Rosser, B. R. S., Bauer, G. R., Bockting, W. O., Robinson, B. E., Rugg, D. L., et al. (2001). Drug use, unsafe sexual behavior, and internalized homonegativity in men who have sex with men. AIDS and Behavior, 5(1), 97-103.

Rowatt, W. C., Cunningham, M. R., \& Druen, P. B. (1999). Lying to get a date: The effects of facial physical attractiveness on the willingness to deceive prospective dating partners. Journal of Social and Personal Relationships, 16(2), 209-233.

Santos, L. H. S. (2004). Educação e pesquisa de práticas sexuais de risco (barebacking sex). In L. F. Rios, V. Almeida, R. Parker, C. Pimenta, \& V. Terto Jr., (Org.). Homossexualidade: Produção cultural, cidadania e saúde. (pp. 69-81). Rio de Janeiro: ABIA.

Scarce, M. (1999). A ride on the wild side. POZ Magazine, 70-71.

Silva, C. G. M., Gonçalves, D. de A., Pacca, J. C. B., \& Hearst, N. (2004). Jovens homens que fazem sexo com homens: Comportamento sexual e antiretrovirais em São Paulo. In L. F., Rios, V. de, Almeida, R., Parker, C., Pimenta, \& V. Terto Jr. Homossexualidade: Produção cultural, cidadania e saúde. (pp. 84-94). Rio de Janeiro: ABIA.
Sistema de Monitoramento de Indicadores do Programa Nacional de DST e AIDS - MONITORAIDS. Indicador de uso de preservativo entre $\mathbf{H S H}$. Recuperado em 30 out. 2008, em http://157.86.8.37/

Sophie, J. (1987). Internalized homophobia and lesbian identity. Journal of Homosexuality, 14(1/2), 53-65.

Sowder, B., \& Beschner, G. (Ed.). (1993). Methamphetamine: An illicit drug with high abuse potential. Maryland: Head and Company.

Stall, R. D., Paul, J. P., Barrett, D. C., Crosby, G. M., \& Bein, E. (1999). An outcome evaluation to measure changes in sexual risk-taking among men undergoing substance use disorder treatment. Journal of Studies of Alcohol, 60(6), 837-845.

Steele, C. M., \& Josephs, R. A. (1990). Alcohol myopia: Its prized and dangerous effects. American Psychologist, 45(8), 921-933.

Suarez, T., \& Miller, J. (2001). Negotiating risks in context: a perspective on unprotected anal intercourse and barebacking among men who have sex with men - where do we go from here? Archives of Sexual Behavior, 30(3), 287- 300.

Vanable, P. A., Ostrow, D. G., McKirnan, D. J., Taywaditep, K. J., \& Hope, B. A. (2000). Impact of combination therapies on HIV risk perceptions and sexual risk among HIV-positive and HIV-negative gay and bisexual men. Health Psychology, 19(2), 134-145.

Van de Ven, P., Prestage, G., Crawford, J., Grulich, A., \& Kippax, S. (2000). Sexual risk behavior increases among HIV negative and HIV positive gay men in Sydney over the four year period prior to February 2000. AIDS, 14, 2951-2953.

Recebido: 29/05/2008 Received: 05/29/2008

Aprovado: 30/10/2009 Approved: 10/30/2009 